\title{
Reseña de Escritos: la literatura infantil, los niños y los jóvenes
}

\author{
Rafael Andrés Porras Suárez ${ }^{1}$
}

Para citar este artículo: Porras, R. A. (2017). Reseña de Es-

Recibido: 03-junio-2016 / Aprobado: 25-septiembre-2017

critos: la literatura infantil, los niños y los jóvenes. Infancias

Imágenes, 16(2), 335-339.

\section{Resumen}

Gran parte del ideario del pensamiento filosófico y estético de Walter Benjamin (1892-1940) se valora en la compilación cronológica de Escritos, realizada por Giulio Schiavoni². Desde su compromiso marxista romántico de la formación de una niñez y juventud proletaria, hasta la valoración genuina por los rastros, huellas y silencios de los artefactos culturales de la infancia alemana (juegos, juguetes y libros) imprescindibles para una "arqueología" histórica de la vida social de la cultura burguesa. Filósofo, teórico marxista, crítico cultural y coleccionista apasionado, "culto y feliz". Benjamin, escrito tras escrito, busca el sentido histórico de la vida moderna y la tradición.

Palabras clave: infancia; juventud; formación; historia; artefactos culturales; cultura infantil.

\begin{abstract}
Great part of philosophical and aesthetic thought of Walter Benjamin (1892-1940) is valued in the chronological compilation of Escritos carried out by Giulio Schiavoni. From his romantic Marxist commitment of the Bildung of a childhood and proletarian youth until the genuine valuation for the trails, traces and silences of the cultural devices of the German childhood (games, toys and books) indispensable for a historical "archaeology" of the social life of the bourgeois culture of his time. Philosopher, theoretical Marxist, cultural critic and passionate collector, "cult and happy". Benjamin, writing after writing, looks for the historical sense of the modern life and the tradition.
\end{abstract}

Keywords: childhood; youth; bildung; history; culture devices; children's culture.

\footnotetext{
1 Licenciado en Psicología y Pedagogía. Maestrante, Maestría en Estudios en Infancias, Universidad Pedagógica Nacional. Correo electrónico: potter_030@hotmail.com

2 Giulio Schiavoni nació en Maiolati Spontini, Italia (1948). Ha sido ensayista y traductor de la literatura alemana de los siglos XVIII y XX. Numerosas de sus publicaciones se concentran en monografías de los intelectuales, filósofos y literatos judeo-alemanes como Kafka, Freud y Benjamin.
} 


\section{Benjamin y su Enciclopedia mágica de la infancia}

¿Por qué y qué escribe un joven como Walter Benjamin? Escribir es el devenir de su pensamiento filosófico y su compromiso histórico y ético (marcado por la clase burguesa y sus raíces judías ${ }^{3}$ ); es, además, el modo adecuado de buscar la "nostalgia" perdida de la infancia (1982, p. 77). En cada texto aparece una figura, una palabra o una leve sombra de la infancia, de su interés por "encontrar y sorprenderse" (al modo del juego del escondite) ante el tesoro oculto de su especificidad mancillado por la pedagogía, la psicología del individuo y la autocontemplación del mundo burgués.

Su corta vida (se suicida a los 48 años antes de caer en manos de la Gestapo) deja grandes elucubraciones que se ven reflejadas en Escritos. Compendio iniciado por la presentación de Schiavoni: "Frente a un mundo de sueño" y 20 escritos que representan su "enciclopedia mágica de la infancia": 1) cuatro textos iniciales (1913 y 1915) acerca del pensamiento filosófico de Benjamin y sus críticas a la sociedad burguesa de su tiempo; 2) 11 textos subsiguientes (1919 y 1930) del interés por la colección de los artefactos culturales infantiles para "hacer historia con los desechos de la historia"; y 3) cinco textos finales (1930 y 1932) de comentarios de cartillas y libros de colección infantil según su agudeza y sensibilidad estética acerca de la Kindische Kultur (cultura infantil).

\section{Críticas a la decadencia del pensamien- to y el conformismo burgués}

El título en alemán del texto reseñado es Über Kinder, Jugend und Erziehung (1969) que alude a la esencia de la escritura de Benjamin: hablar "sobre niños, juventud y educación". Enmarcado en la tradición del materialismo histórico, sus reflexiones filosóficas iniciales apuntan a la base social y moral y no a la crítica socioeconómica como Marx y Engels. La formación moral del espíritu del

\footnotetext{
3 Alemán e hijo de padres judíos, su formación desde infante estuvo estrechamente ligada al conocimiento de su tradición judía, la cual alfabetiza desde temprana edad, generación tras generación, con la lectura de la Torá. De allí, tal vez, la pasión de Benjamin por la lectura, el libro y la escritura como precursores de su pensamiento.
}

hombre [La enseñanza de la moral, 1913] ${ }^{4}$, según Benjamin, está inclinada a la acción ética guiada por un deber ser universal (agregado de los imperativos categóricos kantianos) que no es ajena al "orden de la comunidad" (p. 37). Allí desemboca toda la tradición cultural de la religiosidad. Es acuciante ante la racionalidad utilitarista, biologista y psicologista de la educación moral burguesa y antepone a toda "universalidad" una actitud ética. Benjamin busca una nueva mirada de la educación moral para precisamente denunciar el conformismo ideológico de la tradición moderna alemana que no permite el florecimiento de la novedad, experiencia propia de la infancia y la juventud. "Así es la vida. Lo que nos dicen los adultos es lo que ellos experimentaron. [...] Nosotros conocemos otra experiencia" [Experiencia, 1913]. Plantea en sus textos una pedagogía para liberar al hombre proletariado desde la infancia. La alegoría de su prosa generacional arremete contra el "ritmo del burgués".

Implicado desde joven al Movimiento de la juventud, Benjamin cuestiona la formación del estudiante alemán: formación espiritual [La posición religiosa de la nueva juventud, 1914] y académica [La vida de los estudiantes, 1915]. La juventud posee una significación importante para reproducir el germen del fascismo, sin embargo, Benjamin ve

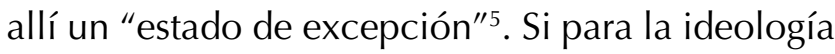
nazi el movimiento juvenil (Juventudes hitlerianas) es fuente de alienación, para el filósofo lo es en el sentido de una lucha social. No duda y reprocha al estudiantado alemán por su conformismo del sueño burgués: la senilidad de la vida del progreso, el anhelo de la profesionalización y el matrimonio. Este señuelo atrapa a una juventud que no cuente con los recursos de espíritu (crítica y creación) para asentir la "seguridad burguesa". La sociedad industrial engalanada de la reserva y la pasividad de pensamiento absorberá el lugar del conocimiento. La universitas cae en la era de la "productibilidad"

\footnotetext{
${ }^{4}$ Las llaves [ ] indican el texto y el año en el que Benjamin desarrolló su crítica, comentario o reflexión.

5 En Tesis de filosofía de la historia (s.f.) referencia a la "tradición de oprimidos", donde incorpora a la juventud, potencia expresada en términos de "estado de excepción", capaz de resistir a los absolutismos de la sociedad del progreso.
} 
donde el "cargo y la profesión" son el ideario dominante, no el saber; ante un sistema apaciguado, la Bildung acaece.

Once textos reflejan el oficio del filósofo por la colección y la bibliofilia. ¿Ya en Benjamin, antes que la microhistoria, hay un interés por la historia hecha por el "desecho" y el "no vencedor"? Sí. Es una historia bifurcada de la hegemonía del progreso, el cientificismo y el historicismo. La historia parte de la nimiedad de los objetos olvidados antaño presa de la autocomplacencia burguesa. "Antropología marxista, dialéctica" Ilama Benjamin al tipo de oficio que realiza al coleccionar y seguir el rastro histórico y social de los artefactos culturales infantiles y sus tradiciones: libros infantiles, juguetes, juegos y teatro, que son a su vez, modos de leer la historia (y la historia de la infancia) en clave de clase social y lucha de la vida familiar del siglo XIX y XX. Con la perspectiva de análisis del materialismo histórico, contribuye a la historia de la sociedad a través de una investigación de la "cultura infantil" (Kindische kultur) atesorada en una "arqueología" de tales artefactos y rastrea el lugar de la infancia, saber y lugar en la "estructura social". Dice: "Hace tiempo que el eterno retorno de todas las cosas se ha convertido en sabiduría infantil" (1982, p. 78) al ver jugar el niño con su juguete.

\section{Rastro de la infancia (Kindheit)}

Benjamin, del primer al último texto, se ocupa de la infancia. Reconoce su ambigüedad en la sociedad y exige reivindicar su especificidad en tanto participe de la lucha de clase [Programa de un teatro infantil proletario, 1928, y Una pedagogía comunista, 1929]. Es claro su rechazo a la pedagogía cambiante (asistémica) consorte de la psicología experimental (basada en universales y métodos) que devalúa el sentido mismo de la infancia por la autocomplacencia adulta. Al decir de Benjamin: Kinder onhe Kindheit (niños sin infancia) (2000).

Según Benjamin, la fundamentación del proyecto de la "educación proletaria" se enmarca "desde los tres hasta los trece años cumplidos". Partir de la visibilidad con que Benjamin habla de la infancia supone una relación estrecha con un interés en la Bildung (formación) y el saber alojado en el espíritu infantil; capital de la clase social proletaria como "generación en potencia". El teatro se convierte en el escenario perfecto para la "realización" de la infancia al desplegar todas sus cualidades: espontaneidad, lucha, expresión y juego, y de reincorporarla a la vida social marcada por la lucha de clases (retoma la educación proletaria bolchevique).

La apuesta formativa benjaminiana es ya un diálogo disciplinar: 1) rastros de una luz sociológica al confesar la necesaria ruptura entre adultos y niñez [André Gide: La porte étroite, 1919]; 2) el ideal constructivista de la comprensión de la infancia y la niñez: "los niños tienden, de manera muy especial, a acudir a todo lugar de trabajo donde visiblemente se manejen cosas. [...] Los niños se forman su propio mundo objetivo, pequeño entre lo grande" (p. 96) [Calle de mano única, 1926-1928]. El niño sabe, ni tabula rasa o determinismo. En cada artefacto se vislumbran cualidades de la infancia.

Los libros para niños (Kinderliteratur)

Benjamin busca en el libro infantil la "nostalgia" de su infancia. Coleccionar cada libro para encontrar algo de sí olvidado: su enciclopedia mágica de su infancia. Memoria de la vida de la infancia burguesa de finales de siglo XIX [Viejos libros infantiles, 1924; Panorama del libro infantil, 1926] o antes [Abecedarios de hace cien años, 1928]. Encuentra el tesoro simbólico con el que cada niño inadvertidamente se sorprende y del cual construye sentido: el acceso a la cultura, el potencial de la imaginación y la creación, el embeleso de la ilustración y la grafía, el juego litográfico del texto colorido o sobrio; en todo caso, la interacción del niño con el texto. Con el libro para niños se descubre al niño-lector. Dirigido al adulto, este transmite al niño la historia, la fantasía, el conocimiento a través del relato. Cada libro infantil coleccionado, del siglo XVIII y XIX, conserva la especificidad del niño amoral, el relato domina el espíritu salvaje. Dos siglos que marcaron la lenta historia del niño: de la diferencia por naturaleza — salvaje/culto- a la diferencia de grado — desobediente/temeroso- La imaginería social transmite al niño vía narrativa 
la culpa, el miedo y la obediencia; la familia juega una notable función al respecto.

El juguete y la historia del juguete (Spielzeug y Geschichte von Spielzeug)

La relación del hombre con el juguete no es nunca la misma del niño [Juguetes antiguos, 1928]. Para los grandes es objeto de "reproductibilidad técnica" para los otros, los pequeños, es una suerte de escogencia; este construye su mundo, el otro, escapa de su realidad ¡Benjamin es un conocedor de la psicología infantil! [Juguetes y juego, 1928]. El niño exige, elige o rechaza, y no se embelesa por la opulencia del objeto ni por el deseo adulto. El niño sabe por qué juega y, de allí, que proscriba su acción lúdica ante un artefacto carente de sentido.

Los juguetes son monumentos de la historia [Historia cultural del juguete, 1928; Juguetes rusos, 1930]. Muñecas, soldados de plomo y estatuillas constituyen un homenaje al pasado ahora anclado en el souvenir. Benjamin reconstruye el lugar histórico del juguete, con ayuda del trabajo de Gröbel, distinguido y ahora apropiado por la industria: del oficio del fabricante de juguetes —arte doméstico - torna a la industria de consumo; de la fascinación por la creación al desencanto del consumo. La historia del juguete tuvo estrecha relación con la evolución histórica de la técnica (pp. 92-115), no con el niño. Sin embargo, el juguete en sí mismo oculta un imaginario histórico de la infancia y se advierte que sus transformaciones implican juegos de poder: "mientras dominó un rígido naturalismo, no existió posibilidad de mostrar el verdadero rostro del niño que juega" (p. 88).

\section{El juego infantil (Die Spielwiesen der Kinder)} El juego es anterior al juguete [Juguetes y juego, 1928] y el niño desconocía al juguete porque "la suposición de que la necesidad misma de los niños determina, sin más, el carácter de los juguetes contiene, pues, un gran error" (p. 91). Sin especificidad del niño, ausente la "cultura infantil". La historia de la infancia denota el carácter indiferenciado del juego. El "juego infantil" adquiere sentido cuando existe el ser "infantil" y unas prácticas diferenciadoras. Benjamín, al leer a Freud, entiende la ley del juego: no es la "imitación" del mundo adulto, sino la "repetición" del goce. Potente idea que mucho después tendrá repercusión pedagógica. Por lo pronto, el filósofo protesta contra la psicología individual y la "pedagogía colonial".

\section{El saber del comentario benjaminiano} Los últimos cinco textos son comentarios críticos [Alabanza de la muñeca, 1930] que Benjamin realiza a diversas obras como conocedor de lo infantil que se place del romanticismo de las cartillas ilustradas [Chichleuchlachra, 1930; Comienzos florecientes, 1931] y arremete contra la psicología "primitiva" del niño que deforma su especificidad y realización [Pedagogía colonial, 1930]. Reitera la voluntad de la formación del hombre (desde la niñez) situando la formación del maestro (Erziehung). Por eso, la reflexión del comentario de Zander sobre Pestalozzi (1746-1827) [Pestalozzi en Yverdon, 1932] quien educó a "los pobres y débiles" ofreciendo "su mano" (p. 142). Esta educación humanista, tal vez, es la que compartió Benjamin en su seno familiar y social y, por proyección, Pestalozzi refleja parte de su pensamiento que además de filosófico, crítico, ético y político, agregaré, es pedagógico.

Sin duda, Benjamin encuentra en las cartillas y libros infantiles un placer infantil que como adulto burgués poco hubiera apreciado. Dice: "sólo quien haya permanecido fiel al placer que le brindaban los libros en su infancia puede descubrir como coleccionista el campo del libro infantil" (1989, p. 65). El placer del libro, su contenido y sentido en las palabras y dibujos, los colores y las letras, la interacción del niño con el texto y el contexto atesorado en las páginas. "Cuando comience a jugar [el niño], de palabra y, de hecho, con lo que acaba de aprender, nuevamente ese libro será su mejor amigo" (p. 137). En Infancia en Berlín hacia 1900 (1982) dedica unas palabras al "juego de letras" que apasiona la vista que persigue formas y colores, y a la mano que crea y dimensiona un mundo: "nada de lo que me ocupaba en mis años mozos evoca mayor nostalgia que el juego de letras" (p. 76). Benjamin reconoce que oculto en el texto está el saber del niño quien da sentido a su vida. 


\section{Referencias}

Benjamin, W. (1982). Infancia en Berlín hacia 1900. Madrid: Alfaguara.

(s.f.). Tesis de filosofía de la historia. Recuperado de: https://www.uv.es/fjhernan/docencia/curs2011_2012/ unimajors2011/Benjamin historia.pdf
. (1989). Escritos. La literatura infantil, los niños y los jóvenes. Buenos Aires: Nueva Visión. (2000). Proletarisches Kindertheater-Programm einer asthetisch-politischen Eriziehung. Berlín: Rogner \& Bernhard. 